\title{
Pseudohypoparathyroidism type la manifesting as intractable epilepsy in a 23-year-old female
}

\author{
This article was published in the following Dove Press journal: \\ International Medical Case Reports Journal \\ 13 July 2012 \\ Number of times this article has been viewed
}

\author{
Pooja Raghavan' \\ Charles $\mathrm{M} \mathrm{Katz}^{2}$ \\ 'Department of Medicine, Mount \\ Carmel Health, Columbus, $\mathrm{OH}$, \\ USA; ${ }^{2}$ Division of Endocrinology and \\ Metabolism, Mount Carmel Health, \\ Columbus, $\mathrm{OH}$, USA
}

\begin{abstract}
Pseudohypoparathyroidism is a rare disorder of calcium metabolism that involves target organ resistance to the action of the parathyroid hormone. As a result, calcium levels may become dangerously low, sometimes leading to seizures and other symptoms. We present a case of a 23-year-old Somalian female on antiepileptic therapy presenting with intractable epilepsy. She was subsequently found to have pseudohypoparathyroidism type Ia. She had multiple reasons accounting for loss of seizure control, including worsening hypocalcemia from resistance to the parathyroid hormone; vitamin D deficiency, which could have resulted from lack of exposure to direct sunlight and her antiepileptic medication; and extensive calcium deposition in the brain due to pseudohypoparathyroidism. The patient was stabilized with intravenous therapy and oral calcium, vitamin D, and calcitriol. Her antiepileptic therapy was changed to a medication that did not interfere with vitamin D metabolism or contribute to worsening hypocalcemia.
\end{abstract}

Keywords: calcium, pseudohypoparathyroidism, epilepsy

\section{Introduction}

Calcium homeostasis, a very tightly regulated system in humans, includes the release of parathyroid hormone (PTH) in response to hypocalcemia. One of the life threatening symptoms of hypocalcemia is seizures. Pseudohypoparathyroidism (PHP), a rare genetic disorder of calcium metabolism, involves target organ resistance to the action of PTH. Thus, despite high serum levels of PTH, hypocalcemia occurs and can lead to seizures, which can be the presenting symptom in patients with PHP. These patients can also develop tetany, convulsions, basal ganglia calcifications, and cataracts.

PHP exists in several forms, with type Ia being the most common. This form involves target organ resistance to other hormones in addition to PTH, including the thyroid stimulating hormone (TSH), growth hormone releasing hormone, and the gonadotropins (LH, FSH). Calcium deposition can occur in the brain, most often in the basal ganglia. PHP type Ia is also associated with a constellation of unusual physical features, known as Albright's hereditary osteodystrophy (AHO), and includes short metacarpals and metatarsals, short stature, and obesity.

We present a case of a 23-year-old Somalian female with intractable epilepsy who was subsequently diagnosed with PHP. The patient had initially maintained seizure control on two antiepileptic medications. However, in the months preceding her admission and diagnosis of PHP, she had loss of seizure control while remaining in the therapeutic range on phenytoin and phenobarbital. The etiology of her recurrent seizures was multifactorial and included hypocalcemia from resistance to PTH, extensive calcium deposition in the basal ganglia and cortex, and exacerbation of
Correspondence: Pooja Raghavan Medical Education; 793 West State St, Columbus, $\mathrm{OH}, 43222$, USA

$\mathrm{Tel}+\mathrm{I} 4048050345$

Fax + I 6I4 457 I0I2

Email pooja.raghavan@alumni.vanderbilt. edu 
hypocalcemia due to vitamin D deficiency. The latter was likely due to restricted exposure to direct sunlight and inhibition of hepatic 25-hydroxylation of vitamin D by certain antiepileptic agents.

\section{Case presentation}

A 23-year-old Somalian female presented to the medical emergency room after her parents noted her to have a tonicclonic seizure at home. Her medical history was significant for mild mental retardation and a seizure disorder, which was diagnosed in Somalia at the age of 18 years. According to the patient's family, the etiology of the seizures was never described, and the patient was started on phenytoin and phenobarbital. She had remained seizure free for the first four years on these medications. Despite therapeutic phenytoin levels, the patient began to have recurring seizures occurring twice monthly for 6 months before admission. The patient had not sought medical attention in the United States prior to this episode due to financial instability.

History was difficult to obtain directly from the patient due to her mental retardation. However, the patient's family was able to provide further details. According to them, the patient had been in relatively good health prior to coming to the emergency room, and had not been hospitalized previously. Over the past 2 years, the patient had complained of intermittent paresthesias in her fingers and toes, along with perioral numbness. She had immigrated to the United States 3 years earlier and lived in Central Ohio, a region with limited sunny days during the winter months. Because of her poor functional status, the patient spent most of her days indoors under the supervision of her parents. Her only home medications were phenytoin and phenobarbital, and she did not use alcohol, tobacco, or illicit drugs. Family history was significant for short stature, short metacarpals, and mild developmental delay in the patient's older brother and mother. The patient also had two other siblings and a father who were of normal stature, had no brachydactyly, and had all completed school in Somalia.

On examination, the patient was alert, but had difficulty answering questions appropriately. She had short stature, a rounded face, and central adiposity, with height and weight measuring $139.7 \mathrm{~cm}$ and $64 \mathrm{~kg}$, respectively. Markedly positive Chvostek and Trousseau signs were elicited. Examination of the extremities revealed brachydactyly of the fingers (Figures 1 and1A) and second, third, fourth, and fifth toes (Figures 2 and 2A). Admission laboratory results are presented in Table 1. An electrocardiogram performed in the emergency room was remarkable for a prolonged QT interval. The patient had no known personal or family history of congenital or

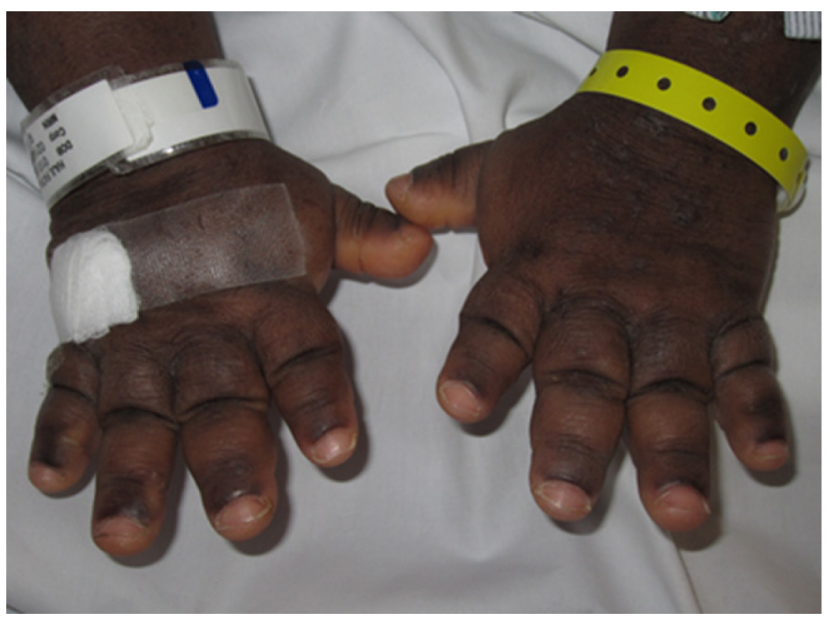

Figure I Note the brachymetacarpals bilaterally along with widened fingernails, suggestive of Albright's hereditary osteodystrophy.

acquired long QT syndrome. Computed tomography of the head revealed diffuse bilateral calcifications throughout the basal ganglia and cerebral cortex (Figures 3 and 3A).

Given the clinical, radiographic, and laboratory findings, presumptive diagnoses of PHP type Ia and mild primary hypothyroidism were made. An Ellsworth-Howard test was performed, which established the presence of resistance to PTH. The patient was admitted to the medical wards, where her hypocalcemia was corrected using both intravenous and oral calcium, vitamin $\mathrm{D}$, and calcitriol. With correction of the hypocalcemia, there was complete resolution of the prolonged QT interval initially seen on electrocardiogram in the emergency room.

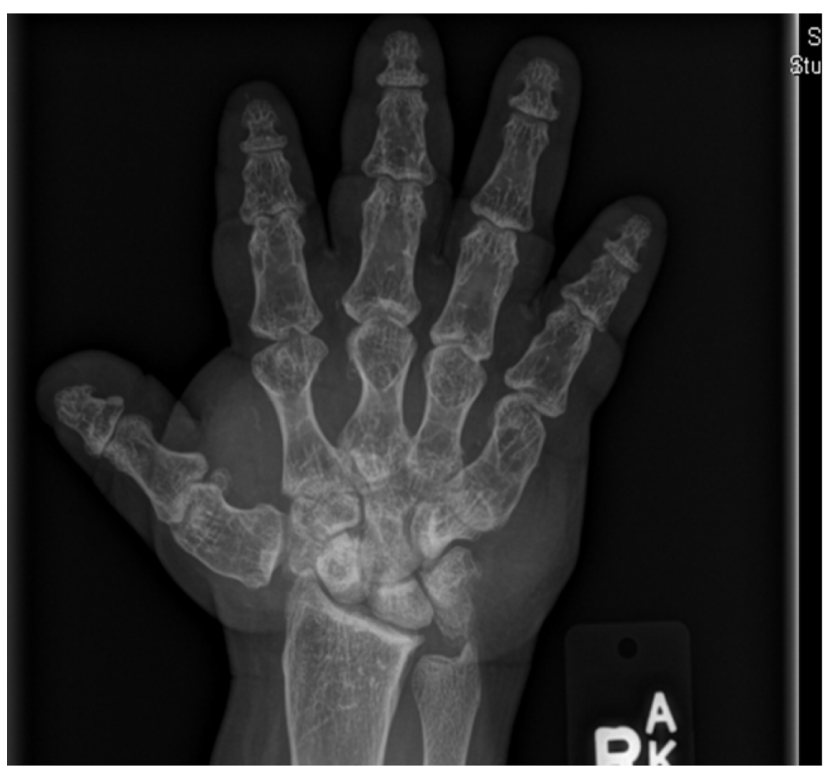

Figure IA Radiograph of the right hand. Note the shortening of each of the metacarpals, including coarsening of the trabeculae in all of the digits. 


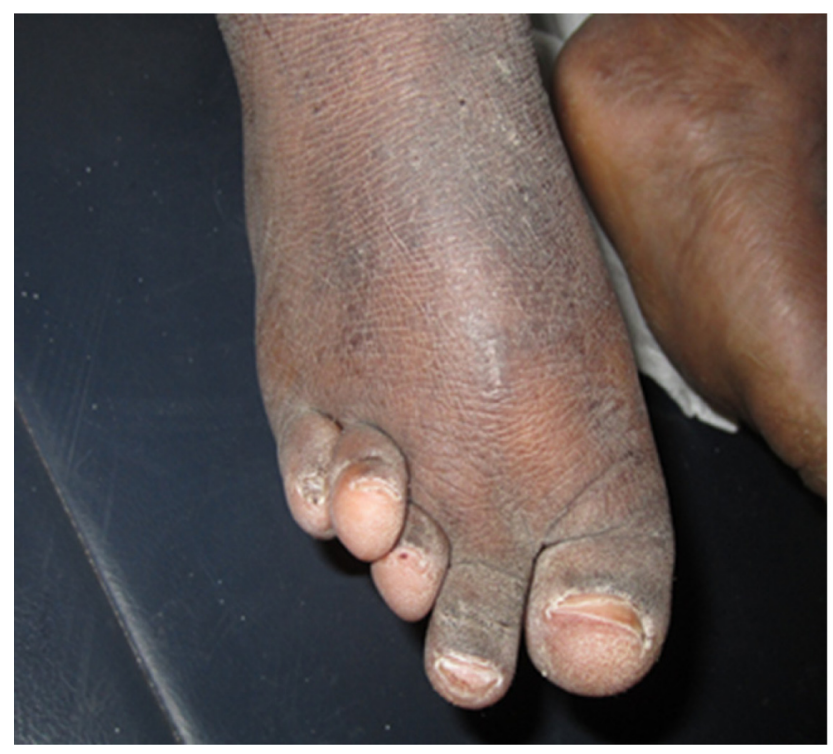

Figure 2 Note the brachymetatarsia of the patient's right foot, characteristically seen in Albright's hereditary osteodystrophy.

The patient was discharged on $112 \mathrm{mcg}$ of levothyroxine daily, $1 \mathrm{~g}$ of calcium carbonate twice daily, 50,000 IU of ergocalciferol weekly, and $0.5 \mathrm{mcg}$ of calcitriol twice daily. Phenytoin was discontinued and the patient was placed on levetiracetam for seizure prophylaxis as it does not interfere with hepatic conversion of vitamin $\mathrm{D}$ to 25 -hydroxyvitamin $\mathrm{D}$. Phenobarbital was gradually tapered down to a lower dosage and eventually discontinued. The patient was followed up at monthly intervals for a duration of 3 months and has remained seizure free since discharge.

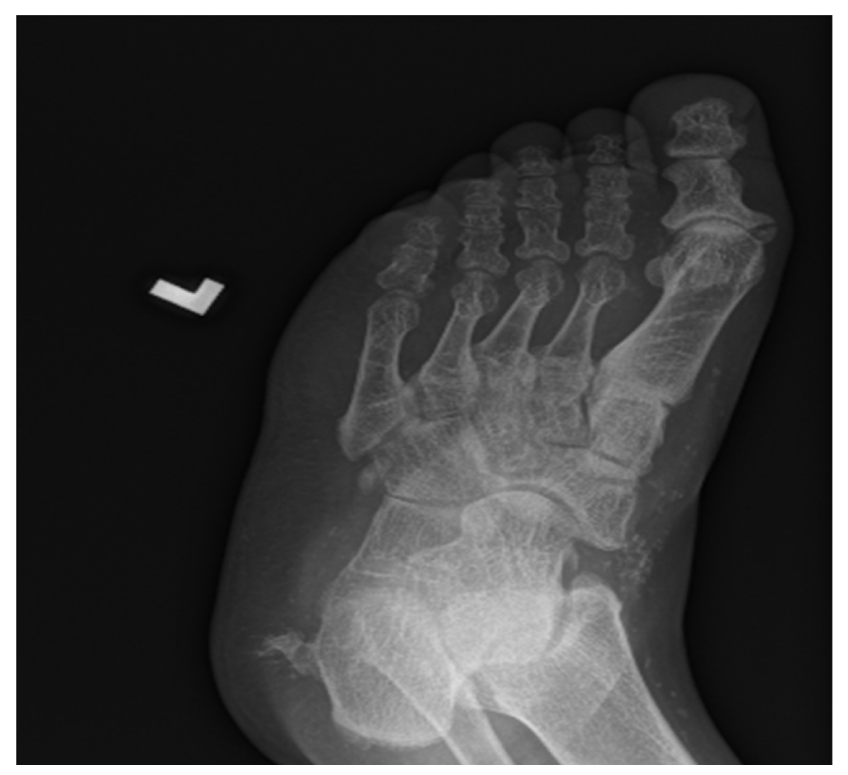

Figure 2A Radiograph of the left foot. The foot appears small with congenitally short metatarsals, especially metatarsals $2,3,4$, and 5 . The proximal phalanges also appear shortened.
Table I Initial laboratory studies ordered upon admission

\begin{tabular}{lll}
\hline $\begin{array}{l}\text { Laboratory test } \\
\text { (units of measurement) }\end{array}$ & $\begin{array}{l}\text { Patient's } \\
\text { values }\end{array}$ & $\begin{array}{l}\text { Normal } \\
\text { reference range }\end{array}$ \\
\hline Serum calcium (mg/dL) & 5.8 & $8.9-10.3$ \\
Serum ionized calcium (mmol/L) & 0.8 & $1.12-1.32$ \\
Serum albumin (mg/dL) & 3.6 & $3.5-4.8$ \\
Serum phosphorus (mg/dL) & 6.6 & $2.4-4.7$ \\
Serum intact parathyroid & 536 & $12-88$ \\
hormone (pg/dL) & & \\
Serum magnesium (mg/dL) & 2.1 & $1.8-2.5$ \\
Serum 25-hydroxyvitamin D & 15 & $30-100$ \\
(ng/mL) & & \\
Serum I,25-dihydroxyvitamin D & 20 & $25-66$ \\
(Pg/mL) & & \\
Serum alkaline phosphatase (U/L) & 128 & $33-115$ \\
Serum thyroid stimulating & 12.93 & $0.34-5.60$ \\
hormone (mlU/L) & & \\
Serum free thyroxine index & 3.78 & $5.93-13.13$ \\
(nmol/L) & & \\
Serum IGF-I at 7 am (ng/mL) & 68 & $116-358$ \\
Serum LH (miu/mL) & 16.7 & $1.2-12.9$ \\
Serum FSH (miu/mL) & 12.5 & $1.8-5.1$ \\
Serum estradiol (pg/mL) & 24 & $95-433$ \\
BUN (mg/dL) & 8.0 & $8.0-20$ \\
Serum creatinine (mg/dL) & 0.77 & $0.60-1.30$ \\
24 hour urine calcium & 34 & $42-353$ \\
(mg Ca/24 hrs) & & \\
\hline
\end{tabular}

Abbreviations: BUN, blood urea nitrogen; FSH, follicle-stimulating hormone; IGF, insulin-like growth factor; LH, luteinizing hormone; U/L, units/liter.

Given the patient's diagnosis of PHP type Ia, the patient's brother and mother, who exhibited the phenotypic appearance of AHO, underwent laboratory evaluation for PHP type Ia and pseudo-PHP. Laboratory results for the patient's brother revealed serum concentrations of calcium,

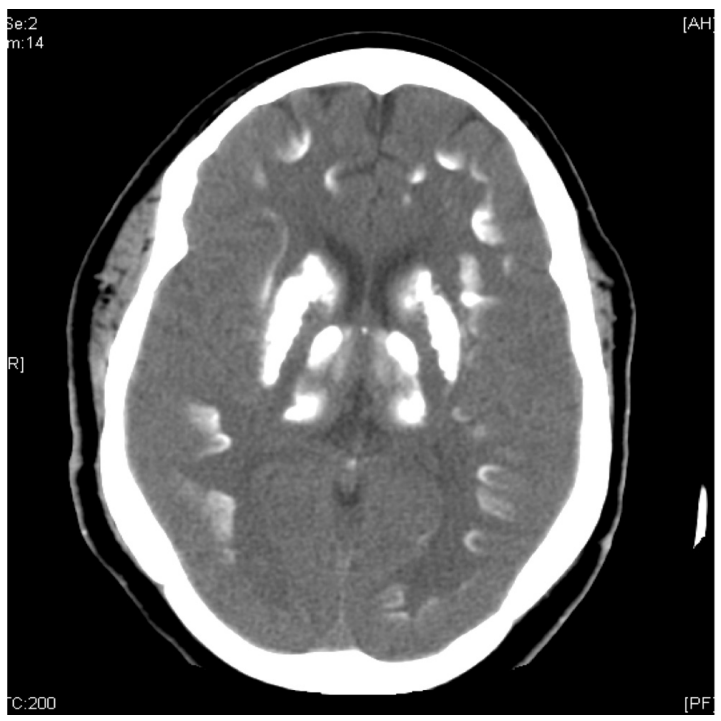

Figure 3 Non-contrast computed tomography of the brain. Intracranially, there are extensive calcifications within the cerebellar hemispheres bilaterally in the basal ganglia and in the parenchyma of the brain. 


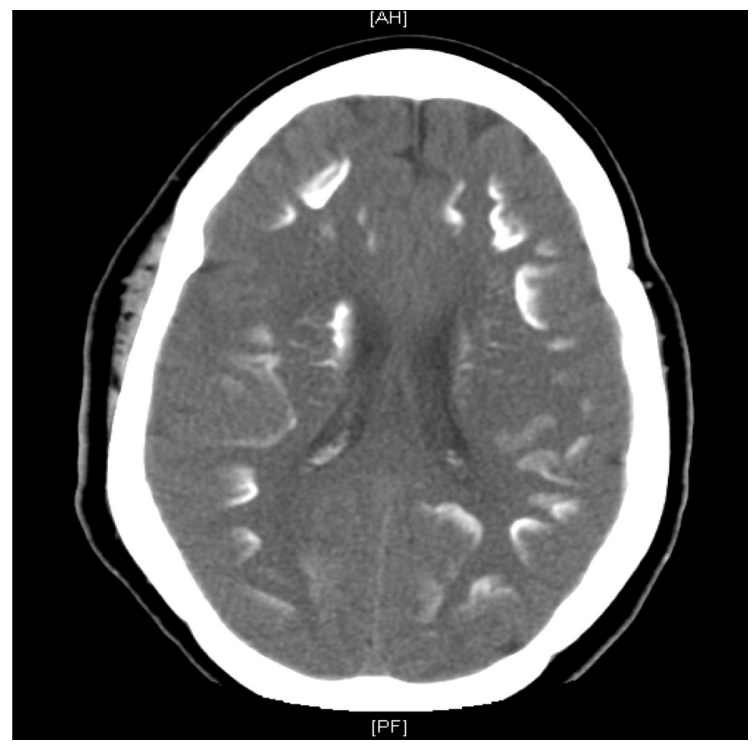

Figure 3A Non-contrast computed tomography of the brain. Note the extensive cortical calcifications within both hemispheres.

phosphorus, and intact PTH to be $7.2 \mathrm{mg} / \mathrm{dL}$ (reference range: $8.9-10.3 \mathrm{mg} / \mathrm{dL}), 5.6 \mathrm{mg} / \mathrm{dL}(2.4-4.7 \mathrm{mg} / \mathrm{dL})$, and $206 \mathrm{pg} / \mathrm{dL}$ (12-88 pg/dL), respectively, suggesting the diagnosis of PHP type Ia. The patient's mother had laboratory testing done, which revealed serum concentrations of calcium, phosphorus, and intact PTH to be $9.0 \mathrm{mg} / \mathrm{dL}, 2.8 \mathrm{mg} / \mathrm{dL}$, and $14 \mathrm{pg} / \mathrm{dL}$, respectively. Due to normal laboratory results in the presence of features consistent with AHO, a tentative diagnosis of pseudo-PHP was made in the patient's mother.

\section{Discussion}

Calcium homeostasis is a tightly regulated system in humans. When the serum calcium falls below normal levels, PTH is released from the parathyroid glands. PTH regulates serum calcium through its effects on bone via bone resorption, the kidneys by promoting the reabsorption of calcium from the distal tubules, and by intestinal calcium absorption, following production of 1,25-dihydroxyvitamin D through PTHinduced activation of the 1-alpha hydroxylase enzyme. ${ }^{1}$

PHP is a rare disease characterized by target organ resistance to the action of $\mathrm{PTH}$, resulting in hypocalcemia and hyperphosphatemia, despite high serum levels of PTH. Few epidemiologic studies of PHP have been conducted due to the rarity of the disease. One recent Japanese study reported an estimated prevalence of 3.4 cases of PHP per million population. ${ }^{2}$

PHP exists as several distinct entities in the form of PHP type I, type II, and pseudo-PHP (Table 2). Type I is differentiated from type II and pseudo-PHP based on the response to administration of synthetic PTH, known as the Ellsworth-Howard test ${ }^{3}$ There are three subtypes of PHP type I. PHP Ia, the most common type, is inherited in an autosomal dominant pattern and is caused by an inactivating mutation in the GNAS gene that encodes the alpha subunit of the stimulatory G-protein (Gs $\alpha) .{ }^{4}$ This signaling protein is involved in the actions of PTH and several other hormones. When PTH binds to its receptor, Gs $\alpha$ activates adenyl cyclase, which is responsible for signal transduction, which produces the response to PTH in target tissues. The inactivating mutation in the GNAS gene ultimately leads to failure of signal transduction, resulting in the inability of the target tissues to respond to PTH. ${ }^{5}$ PHP Ia not only involves end organ resistance to $\mathrm{PTH}$, but can also involve tissue resistance to other hormones that share the similar signaling pathway through Gs-coupled receptors, including TSH, LH, FSH, and growth hormone releasing hormone. ${ }^{6,7}$

The occurrence of PHP involves a heterozygous loss of function mutation in the GNAS gene and a phenomenon termed genomic imprinting, in which the GNAS gene is expressed in tissues in a parent-specific manner. ${ }^{8}$ When an allele associated with the GNAS gene is imprinted from one parent, this allele is inactivated or poorly expressed. Thus, the gene is expressed from the non-imprinted allele inherited from the other parent. Patients with PHP Ia and pseudo-PHP exhibit about $50 \%$ activity of Gs $\alpha$ in unimprinted tissues. However, in certain tissues, such as the renal proximal tubules, the thyroid, and the gonads, the paternal allele of the GNAS gene is imprinted. ${ }^{9}$ Thus, the gene is expressed from the maternal allele in these tissues. ${ }^{8-10}$ This explains why maternal inheritance of a heterozygous loss of function mutation in the GNAS gene with the paternal allele being imprinted results in PHP Ia, which involves end organ resistance to PTH, TSH, $\mathrm{LH}$, and FSH, while paternal inheritance of a heterozygous loss of function mutation in the GNAS gene results in pseudoPHP, which involves no associated hormonal resistance. ${ }^{6-11}$ Thus, the patient and her brother inherited the gene from their mother and had PHP Ia. Their mother probably inherited it from her father and had pseudo-PHP.

PHP Ia and pseudo-PHP are both associated with AHO, which is characterized by a constellation of unusual physical features, including short stature, obesity, round face, brachymetacarpals, brachymetatarsia, dental hypoplasia, and ectopic ossifications. The AHO phenotype in conjunction with end organ resistance to several hormones, including PTH, constitutes the syndrome of PHP Ia. ${ }^{11,12}$ The AHO phenotype with no associated hormonal resistance constitutes the syndrome of pseudo-PHP. 
Table 2 Differentiating the multiple subtypes of PHP

\begin{tabular}{llllllll}
\hline $\begin{array}{l}\text { PHP } \\
\text { subtype }\end{array}$ & $\begin{array}{l}\text { Serum } \\
\text { calcium }\end{array}$ & $\begin{array}{l}\text { Serum } \\
\mathbf{P}\end{array}$ & $\begin{array}{l}\text { Serum } \\
\text { PTH }\end{array}$ & $\begin{array}{l}\text { Urine cAMP after } \\
\text { synthetic PTH } \\
\text { administered }\end{array}$ & $\begin{array}{l}\text { AHO } \\
\text { features }\end{array}$ & $\begin{array}{l}\text { Multi-hormone } \\
\text { resistance }\end{array}$ \\
\hline PHP la & Low & High & High & Low & Yes & Yes \\
of Gs $\alpha$
\end{tabular}

Abbreviations: PHP, pseudohypoparathyroidism; P, phosphorous; PTH, parathyroid hormone; cAMP, cyclic adenosine monophosphate; AHO, Albright's hereditary osteodystrophy; Gs $\alpha$, alpha subunit of the stimulatory G-protein.

Characteristic laboratory and imaging findings are also associated with PHP Ia. Resistance to PTH in target tissue will cause hypocalcemia and hyperphosphatemia despite high serum levels of PTH. Mild resistance to other hormones may be seen, including resistance to TSH, growth hormone releasing hormone, LH, and FSH. A characteristic finding on computed tomography of the brain is calcification of the basal ganglia, but extensive intracranial calcifications may rarely be seen. ${ }^{13,14}$

Our patient presented with intractable epilepsy, and during the work up to elucidate the etiology of her recurrent seizures, she was found to have PHP Ia. The cause of the patient's seizure activity was multifactorial. The causes included direct and indirect effects of PHP, as well as vitamin D deficiency. The PHP caused extensive calcifications of the basal ganglia and cerebral cortex. It also contributed to the severe hypocalcemia, which was exacerbated by the vitamin D deficiency. The latter was probably due to a combination of restricted exposure to direct sunlight and inhibition of hepatic 25-hydroxylation of vitamin $\mathrm{D}$ by the patient's antiepileptic medication.

Calcification of the basal ganglia is a rare phenomenon, and approximately $70 \%$ to $80 \%$ of cases are caused by a disorder of calcium metabolism, such as hypoparathyroidism and PHP. ${ }^{13}$ Other pathologic causes of symmetric bilateral basal ganglion calcification include Fahr's syndrome, Down syndrome, Cockayne syndrome, and tuberous sclerosis, but none of these syndromes present with the laboratory findings or physical features of AHO that are characteristic of PHP Ia. ${ }^{15}$ The presence of a metabolic cause for bilateral basal ganglion calcifications, such as hypocalcemia due to PHP Ia, effectively rules out the other aforementioned syndromes. It has been suggested that vascular insufficiency in the extrapyramidal system causes this characteristic deposition of calcium in the basal ganglia, but there have been no data to definitely support this claim. ${ }^{13,16}$ Approximately $50 \%$ of patients with PHP exhibit localized calcification of the basal ganglia. ${ }^{17}$ Extensive calcification of the cerebral cortex extending beyond the basal ganglia, however, is a rare finding. ${ }^{17}$ When detected on imaging studies, these findings result in a diverse clinical presentation, including seizures, mental deterioration, and Parkinsonism, although some patients may remain asymptomatic. ${ }^{13}$ Our patient presented with extensive bilateral intracranial calcifications involving the basal ganglia and cerebral cortex, which may have contributed to intractable epilepsy.

Paradoxically, another factor shown to contribute to loss of seizure control is long-term antiepileptic therapy, particularly phenytoin, phenobarbital, and carbamazepine. These antiepileptic medications induce hepatic microsomal enzymes that convert 25-hydroxyvitamin $\mathrm{D}$ to inactive metabolites, resulting in low levels of vitamin D. ${ }^{18}$ This leads to low levels of 1,25 dihydroxyvitamin $\mathrm{D}$, impaired absorption of calcium from the intestine, and reduced mobilization of calcium from bone, further exacerbating hypocalcemia. ${ }^{19}$ Laboratory results in these patients will show low serum levels of 25-hydroxyvitamin D, 1,25-dihydroxyvitamin $\mathrm{D}$, and calcium. If a compliant patient on antiepileptic therapy presents with loss of seizure control, clinicians must consider the possibility of antiepileptic induced hypocalcemic seizures. In a patient with PHP Ia who presents with loss of seizure control after previously being stable on antiepileptic therapy, an even further exacerbation of hypocalcemia may occur, resulting in intractable epilepsy. In these patients, hypocalcemia should be treated with supplementation of vitamin D and calcium, and efforts should be made to convert the patient to antiepileptic medications that do not interfere with vitamin D metabolism.

Finally, in patients with dark skin who have minimal exposure to sunlight, vitamin D deficiency may occur. Vitamin D is acquired mainly through direct exposure to sunlight, though diet may also influence levels to some degree. ${ }^{20}$ In order to optimize calcium absorption in the intestine, adequate levels of vitamin D are required. ${ }^{21}$ Our patient from Somalia with dark skin who had little exposure to direct sunlight during the winter months in the Midwest region of the United States was deficient in vitamin $\mathrm{D}$. This further exacerbated hypocalcemia, resulting in intractable epilepsy. 
Though the etiology of intractable epilepsy in the setting of PHP Ia is multifactorial, certain factors can be controlled and lead to improvement in seizure control. Calcium and vitamin D should be adequately replaced, and antiepileptic medications that interfere with vitamin D metabolism should be avoided.

\section{Conclusion}

Calcium homeostasis is a tightly regulated system in humans. In patients with disorders of calcium metabolism, severe hypocalcemia may occur, resulting in seizures. Multiple factors may cause ineffective seizure control in these patients. Thus, physicians should be cognizant of disorders of calcium metabolism and medications that can exacerbate hypocalcemia, resulting in loss of seizure control. PHP Ia, a rare genetic disorder of calcium metabolism, may initially present as hypocalcemic seizures. In patients with disorders of calcium metabolism, such as PHP Ia, who have a concomitant seizure disorder, caution should be placed on choice of antiepileptic therapy as certain medications may paradoxically exacerbate seizures by further lowering serum calcium levels. Emphasis should be placed on correcting hypocalcemia with vitamin D and calcium supplementation. Life-long supplementation with calcium and vitamin $\mathrm{D}$ will be required in these patients to maintain sufficient calcium levels and prevent progression of the disease. . $2,23^{23}$

\section{Disclosure}

The authors report no conflicts of interest in this work.

\section{References}

1. Poole KE, Reeve J. Parathyroid hormone - a bone anabolic and catabolic agent. Curr Opin Pharmacol. 2005;5(6):612-617.

2. Nakamura Y, Matsumoto T, Tamakoshi A, et al. Prevalence of idiopathic hypoparathyroidism and pseudohypoparathyroidism in Japan. J Epidemiol. 2000;10:29-33.

3. Okazaki R. Differential diagnosis of hypoparathyroidism and the Ellsworth-Howard's test. Clin Calcium. 2007;17(8):1182-1185.

4. Mantovani G, Sanctis L, Barbieri A, et al. Pseudohypoparathyroidism and GNAS epigenetic defects: clinical evaluation of Albright hereditary osteodystrophy and molecular analysis in 40 patients. J Clin Endocrinol Metab. 2010;95(2):651-658.

5. Mantovani G, Bondioni S, Linglart A, et al. Genetic analysis and evaluation of resistance to thyrotropin and growth hormone-releasing hormone in pseudohypoparathyroidism Type Ib. J Clin Endocrinol Metab. 2007;92: $3738-3742$

International Medical Case Reports Journal

\section{Publish your work in this journal}

The International Medical Case Reports Journal is an international, peer-reviewed open-access journal publishing original case reports from all medical specialties. Previously unpublished medical posters are also accepted relating to any area of clinical or preclinical science. Submissions should not normally exceed 2,000 words or
6. Mantovani G, Maghnie M, Weber G, et al. Growth hormone-releasing hormone resistance in pseudohypoparathyroidism type Ia: new evidence for imprinting of the Gs $\alpha$ gene. J Clin Endocrinol Metab. 2003;88: 4070-4074.

7. Levine MA, Downs RW Jr, Moses AM, et al. Resistance to multiple hormones in patients with pseudohypoparathyroidism. Association with deficient activity of guanine nucleotide regulatory protein. Am J Med. 1983;74:545-556.

8. Weinstein LS, Yu S. The role of genomic imprinting of Gs $\alpha$ in the pathogenesis of Albright hereditary osteodystrophy. Trends Endocrinol Meta. 1999;10(3):81-85.

9. Mantovani G, Ballare E, Giammona E, et al. The Gs $\alpha$ gene: predominant maternal origin of transcription in human thyroid gland and gonads. J Clin Endocrinol Metab. 2002;87:4736-4740.

10. Nakamoto JM, Sandstrom AT, Brickman AS, et al. Pseudohypoparathyroidism type Ia from maternal but not paternal transmission of a Gs $\alpha$ gene mutation. Am J Med Genet. 1998;77:261-267.

11. Weinstein LS, Yu S, Warner DR, et al. Endocrine manifestations of stimulatory $\mathrm{G}$ protein $\alpha$-subunit mutations and the role of genomic imprinting. Endocr Rev. 2001;22:675-705.

12. Mariot V, Maupetit-Mehouas S, Sinding C, et al. A maternal epimutation of GNAS leads to Albright osteodystrophy and parathyroid hormone resistance. J Clin Endocrinol Metab. 2008;93:661-665.

13. Koller WC, Cochran JW, Klawans HL. Calcification of the basal ganglia: computerized tomography and clinical correlation. Neurology. 1979;29(3):328-333.

14. Litvin Y, Rosler A, Bloom RA. Extensive cerebral calcification in hypoparathyroidism. Neuroradiology. 1981;21(5):271-272.

15. Basak RC. A case report of basal ganglia calcification - a rare finding of hypoparathyroidism. Oman Med J. 2009;24(3):220-222.

16. Norman RM, Urich R. The influence of a vascular factor on the distribution of symmetrical cerebral calcification. J Neurol Neurosurg Psychiatry. 1960;23:142-147.

17. Montenegro AC, Gelenske T, Higino de Carvalho E, et al. First description of pseudohypoparathyroidism with frontal lobe calcification and normal serum calcium at the initial manifestation in an otherwise healthy seven-year-old girl. Arq Bras Endocrinol Metab. 2011;55(5): 349-352.

18. Hahn TJ. Drug-induced disorders of vitamin D and mineral metabolism. Clin Endocrinol Metab. 1980;9:107-127.

19. Ali FE, Al-Bustan MA, Al-Busairi WA, et al. Loss of seizure control due to anticonvulsant-induced hypocalcemia. Ann Pharmacother. 2004;38: $1002-1005$.

20. Van Rooijen CR, Kok MB, Simsek S, et al. Aint no sunshine when she's gone: pseudohypoparathyroidism discovered in an adult. Case Reports in Endocrinology. 2012:Article ID 739375.

21. Heaney RP. Functional indices of vitamin D status and ramifications of vitamin D deficiency. Am J Clin Nutr. 2004;80(Suppl): 1706S-1709S.

22. Qu L, Zhang TT, Mu YM. Clinical analysis of 15 cases of pseudohypoparathyroidism. Nan Fang Yi Ke Da Xue Xue Bao. 2012; 32(5):685-6856.

23. Wang O, Xing XP, Meng XW, et al. Treatment of hypocalcemia caused by hypoparathyroidism or pseudohypoparathyroidism with domesticmade calcitriol: a prospective and self-controlled clinical trial. Chin Med J. 2009;122(3):279-283.

4 published pages including figures, diagrams and references. The manuscript management system is completely online and includes a very quick and fair peer-review system, which is all easy to use. Visit http://www.dovepress.com/testimonials.php to read real quotes from published authors. 